\title{
Annual Traveller Demand from Advertising and Word of Mouth
}

\author{
Saisomphorn Larhsoukanh ${ }^{1 *}$, Chengzhang Wang ${ }^{1}$ \\ ${ }^{1}$ School of Economics and Management \\ Email: saisomphorn@live.com
}

\begin{abstract}
To acquire an information regarding the best travel destination, there are two main sources which can be used: advertising (books and magazines, TV, radio, and travel agencies) and word-of-mouth recommendations (WOM) via the Internet and friends. This study employed two research questions. First, how does advertising influence WOM, and vice versa. Second, to tackle the unsolved problem regarding how to predict traveler demand using WOM that can help improving tourism competitiveness. By using static demand and quadratic cost function, the authors found that advertising generates optimal outcome in tourism industry rather than WOM. Although the player's (the tourism industry in a country) net profit tends to have a positive effect on optimal advertising investment, it is the opposite case if WOM is used. WOM can be detrimental to an agent's advertising campaigns, and may create disadvantage on tourism competition.
\end{abstract}

\section{Type of Paper: Empirical}

Keywords: Word of Mouth (WOM); Advertising; Tourism demand forecast; Optimization; Game theory

\section{Introduction}

Tourism in the CLMV countries, including Cambodia, Laos, Myanmar, and Vietnam, has been experiencing a remarkable growth (see Figure 1). In 1995, the famous ancient city of Luang Prabang in Laos joined the list of World Cultural heritage sites. A year later, the number of tourists arrived in Laos was approximately 60,000. However, as of 2014, the number of tourists in Laos had reached 3.77 million. Is this phenomenon a reflection of Laos's investment on advertisement, or is it simply a growing trend in the regional tourism industry, or is it because of word-of-mouth recommendations?

To answer the question, comparing the ad efforts in tourism industry in Laos and Thailand, particularly through the mobile phones, is needed. In Laos, there are very few smartphone tourism applications. If someone types the key words "tourism+Laos", or "travel+Laos," he/she will find few tourism applications for iOS or iPhone ${ }^{1}$. However, a search for tourism information for Thailand, a richer neighboring country, produces multiple results for apps with the keywords "thai+travel+tourism." This study chose to centralize its focus on mobile advertisement because most of the companies are shifting their ad dollars (TV advertisements)

\footnotetext{
${ }^{1}$ Searched on 11 July 2017
} 
to mobile phones ${ }^{2}$. The example of this is Adidas, which is widely known to be a major advertiser and shoes producer.

The Lao government must have an intervention on its tourism activity to improve its competitiveness (Porter, 1990). However, as a developing country, it provides only a small amount of funding and subsidies for tourism advertising - approximately USD 0.2 million in the fiscal year 2015-16. However, the government advertising budget was slightly higher in the previous fiscal year 2014-15, with spending at USD 0.4 million. Unfortunately, in early April 2016, the Lao National Assembly announced further budget cuts for the upcoming fiscal year 2016-17 due to the area's continuing fiscal conditions in the past few years. On $30^{\text {th }}$ July 2016, the Lao government joint the collaborative alliance on marketing in CLMV under the theme "Four Countries, One Destination" (see Figure 2). This can be considered as a good expenditure. Hence, the answer to the first part of the above question regarding the ad efforts might be not satisfactory, because it seems that the Lao government and its tourism industry including tourism supply chain (TSC) (see Figure 3) do not invest heavily in advertisements, especially through the new media channels such as mobile ads, which suggests for a need of the country to invest in traditional marketing and advertising.

This study aims to address the above questions and tackle some unsolved problems regarding word-of-mouth (WOM) communication. WOM seems to be effective in identifying Laos as a backpacker's destination. As Litvin et al. (2008) observed, when a customer is about to decide to purchase something, WOM is considered the most significant information source. Evidently, according to a travel survey done by the Lao Tourism Development Department (2014), 55.8\% of visitors got information about Laos via the Internet and friends (see Figure 4). WOM and electronic WOM (eWOM) appear to be "cheap," and may help a marketing manager break down consumer defenses (Boyer, Edmondson, Baker, \& Solomon, 2015). However, the number of studies that address how advertising efforts influence WOM and vice versa, or how to predict traveler demand based on advertisement versus WOM, is limited.

The main contributions of this study are twofold. First, by adopting a new demand model, the authors applied the quadratic costs of advertising efforts to write a simple equation for future marketing (advertising) direction based on WOM. Specifically, how WOM "guarantees" tourism firm's profit in short period of time. Second, the authors attempted to foster a relationship between advertising efforts and WOM.

\section{Recent Related Literature}

This study established the interactions among advertising efforts and/or cooperative advertising, and WOM in supply chain management (SCM), particularly the tourism supply chain (TSC), by applying optimization method. In fact, as mentioned in the introduction, the authors began with using quadratic ad costs (Jørgensen \& Zaccour, 2014) to uncover managerial insights concerning the contributions of the above interactions. Accordingly, recent literature related to these interactions was reviewed.

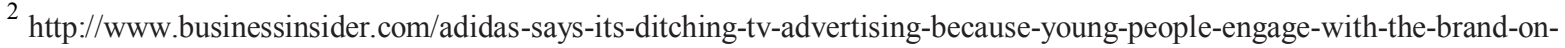
mobile-2017-3 (accessed on May 6, 2017)
} 


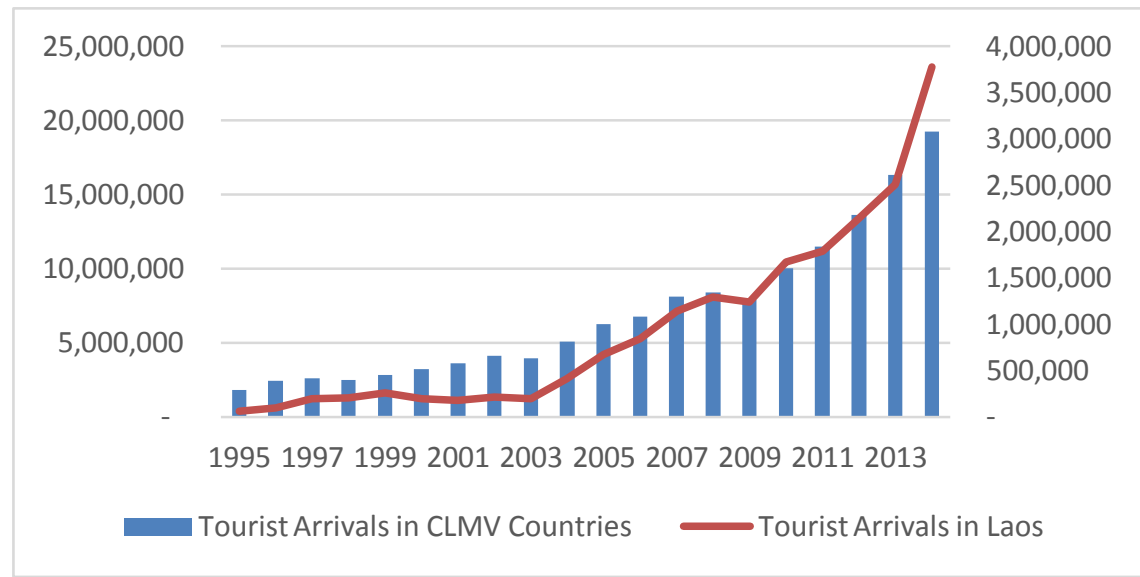

Figure 1. Trend on tourist arrivals in Laos and in CLMV Countries. The data was obtained from the Ministry of Information, Culture, and Tourism of Laos, and the World Bank ${ }^{3}$.

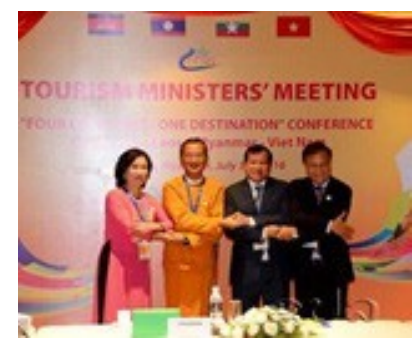

Figure 2. CLMV's Tourism Minister Meeting on July 30, 2016

\begin{tabular}{|c|c|c|}
\hline $\begin{array}{c}\text { Pre-delivery } \\
\text { Support }\end{array}$ & Tourism Supply Chain (TSC) Management & $\begin{array}{c}\text { Post-delivery } \\
\text { Support }\end{array}$ \\
\hline & Delivery & \\
\hline
\end{tabular}

Figure 3. Traveler flow and players of Tourism Supply Chain. According to Reece (2010), Y1lmaz and Bititci (2006), and Collier and Evans (2007), four players exist in the TSC, including, Tour Operators and Travel Agents (O), Transport and Airlines Providers (T), Hotel, Accommodations, and Restaurants Providers (H), and Destinations, Events and Attractions Providers (D).

\subsection{Advertising effort including cooperative advertising over social media and internet}

Since 2013, several studies have attempted to focus on marketing efforts via social media and the Internet using game theory of Stackelberg leader-follower situations (see Xiang and Shan, 2013; Lei et al., 2015). Xiang and Shan (2013) found that a leader with online consumer reviews (OCR) in a supply chain can increase marginal revenue in comparison to any followers because the OCR performs as either a communication tool, or a marketing effort. However, in

\footnotetext{
${ }^{3}$ http://data.worldbank.org/indicator/ST.INT. ARVL (accessed in August 2016).
} 


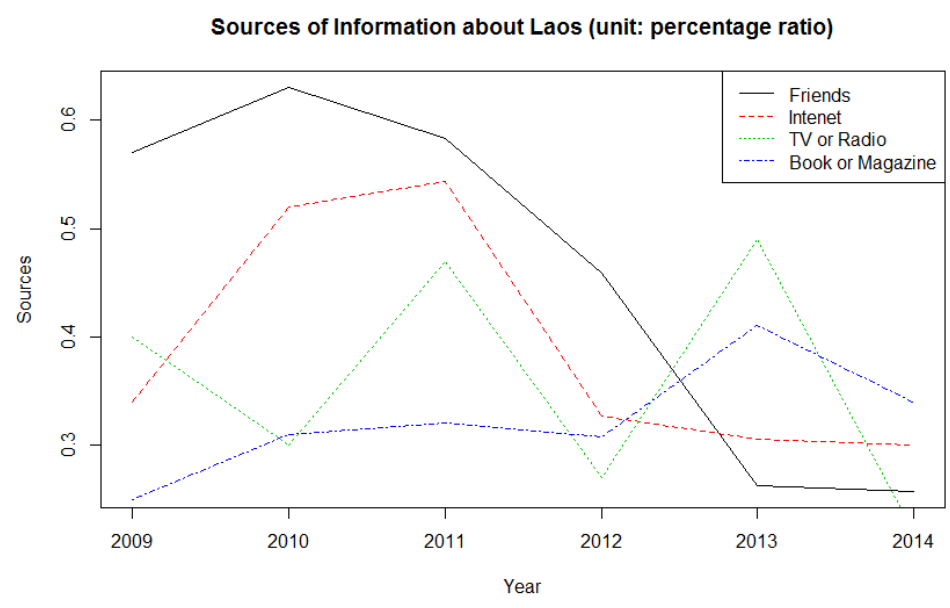

Figure 4. Source of information about Laos

a cooperative game, the OCR can also bring reasonable profits to both the manufacturer and the retailer. Moreover, if a retailer devotes marketing efforts to its only retail channel, such as the Internet, then the manufacturer's channel results will be conclusively determined by price elasticity, sales income, market share ratio, channel fees, and rise and fall in demand (Lei et al., 2015). In addition to the Stackelberg et al. (2014) analyzed dynamic brand and advertising channels by using differential games. Their results confirm that online marketing compatibility increases the advertising investment of a product. It indicates that brand advertisement through online channel may stimulate the total demand of a product. However, unlike Sayadi and Makui (2014), this study briefly explore the rate of brand influence in comparison to WOM and ad ratios.

In terms of cooperative advertising, Jørgensen and Zaccour (2014) found in their survey that most studies use similar unsophisticated equations to address consumer demand in noncooperative games. For example, they only address vertical interactions, such as a manufacturer and a retailer. In addition, the second part of their literature review highlights that model results with horizontal cooperation are heavily dependent upon inter-and-intra-brand rivalry. In other words, this level of cooperation may not work well in a marketing channel. However, as Yan and Pei (2015) argue, the more Internet-compatible a product is, the more responsive the retailer to heavier investment in cooperative advertising. In this case, the manufacturer also needs to increase the level of cooperation. However, these studies forgot to explain WOM's role in the marketing strategies.

\subsection{Ad versus WOM}

At the same time, Avagyan et al. (2014) emphasize the "S curve" phenomenon of accelerating new product diffusion through licensing companies. Specifically, WOM through a licensee's consumers and advertisements can expand sales indirectly, meaning that WOM and advertising are jointly responsible for business development. However, in this study the opposite is probably true.

\subsection{Predicting demand}

Projecting tourism demand in a country by using TSC's advertising or other parameters is 
a complex problem. Recently, several studies have already applied game theory in the area. Hung-Teng (2014) studied demand projection in the food and beverage industry based on the challenges of coping with immediate customer demand. The author found that an inventory management model is the key to demand forecasting accuracy. In another important study, Slimani et al. (2015) conduct a survey of game theory application and neural networks to identify the optimal-multi-layer-perception arrangement. The study results show that neural networks may help estimate consumer demand. However, this study goes beyond advertising to explore the role WOM plays in demand forecasting.

\section{Model Framework}

This section attempted to define method description. One may think of a situation in which this study acts as a non-cooperative game theory. Although tourism industry is the only player of the game in this study, it has four groups of players (see Figure 3). The players, besides strategic moves and payoff (outcome) of the game, are one of the three main features of game theory. However, this study investigates the optimal payoff of the advertising game. To present the study, the notation as shown in Table 1 is used.

\subsection{Backpackers vs. Package Tours}

In terms of tourist arrivals (tourism demand), it can be categorized into two groups, package tours and independent travelers (i.e., backpackers) (Yilmaz and Bititci, 2006). To be exact, we refer to Figure 5. Generally, package tours use player O's service, but they benefit from both the TSC's and the Government's (i.e., Authority of Tourism Marketing) advertising campaigns, because these collaborative stakeholders depend heavily on ad campaigns to improve their country's brand and image, as well as to attract customers (i.e., visitors). By definition, a package tour involves either buying an entire vacation package, or a small part of it such as buying only an airline ticket, or booking a hotel. Although a backpacker's choices are based on individual preference, they are mostly following WOM recommendations (Lao Tourism Development Department, 2014). Undeniably, ad and WOM go hand in hand, and consistently reinforce each other positively or negatively.

\subsection{One-period Traveler Demand}

By using first-order difference equation, the estimation of tourism demand using a WOM determinant can be made. First, the number of tourist arrivals is the favored measurement of traveler demand (Song \& Li, 2008). Let be tourism demand (number of tourist arrivals) in a country at time . Let denote WOM influencing rate, or the WOM percentage ratio of information source which backpackers find to visit a country, and . In addition, our assumption

Table 1. Main notation used in the study

\begin{tabular}{cl}
\hline$D$ or $D_{t}$ & Tourism demand in a country or at time $t$ \\
$\omega$ & The WOM influencing rate \\
$\delta, \vartheta, \varphi$ & Positive numbers \\
$k$ & The rate of advertising effect \\
$A$ & Advertising expenditures \\
$\pi$ & Average net profit in tourism industry in a country \\
\hline
\end{tabular}



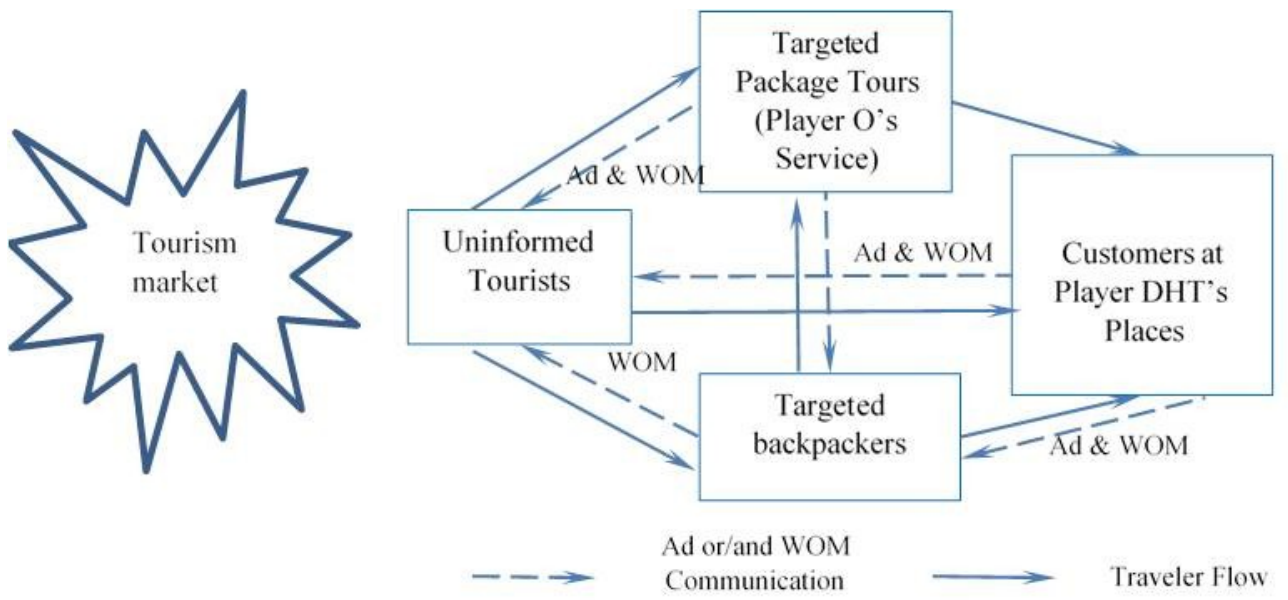

Figure 5. Block-diagrtaam of the TSC players and of traveler flow into a feedback of communication channels and their analytical parameters

is tacitly supported by WOM percentage ratios based on friends and the Internet in Figure 4. Graphically, if we plot against time in the positive quadrant, then we need to concern ourselves with the hyperbolic curve represented by

$$
\omega_{t+1}=\frac{\omega_{t}}{t+1}
$$

Notably, Chen, Yang, and Wang (2016) also emphasize the downward direction of eWOM in online market. In other words, WOM may follow downward trend is elastically in discrete time. Therefore, resting on discrete time, the difference between traveler demand at time, and at time is. Where is positive numbers, which can act for number of visitors in Laos from rising trend in Asian travel at time. Equivalently, we can write another difference equation based on equation as . Essentially, if is being interpreted as WOM influencing rate in the based year (or initial value), then can be tourism demand in the based year (e.g., this year), too. As Chiang and Wainwright (2005) suggest at page 548, can be "the general multiplicative constant".

However, one of the purposes of this study is to foster the relationship between ad and WOM efficiency. Let $A_{t}$ and $\vartheta_{t}$ be TSC's advertising expenditures and positive constant, respectively, which are given at time $t$. We satisfy the equation $D_{t}=\vartheta_{t} A_{t}$ for the multiplicative constant. Without loss of generality we obtain tourism demand function based on ad investment, that is, $D_{t+1}=\delta_{t}+\omega_{t} \vartheta_{t} A_{t} /(t+1)$. In practice, advertising is often to generate short-term demand (Huang \& Li, 2001), or one-year demand. Accordingly, we may refer to $t=1$. As a result, $D_{t+1}=\delta_{1}+\omega_{1} \vartheta_{1} A_{1} / 2$. Clearly, we can forecast the tourism demand on an annual basis as follows:

$$
D=\delta+\frac{\omega}{2} \vartheta A
$$




\section{Results and Discussion}

In non-cooperative games and in for-profit firms, rational players often seek for maximized profit. The authors see analogous clarifications in the following findings. First, in order to look for contributions to national policy implications for tourism industry competitiveness, we employ quadratic costs of advertising (Jørgensen \& Zaccour, 2014) in tourism industry or TSC. Accordingly, based on one-period tourism demand, the objective function of the firm is to maximize, or

$$
\text { to maximize } J(A)=\pi\left(\delta+\frac{\omega}{2} \vartheta A\right)-\frac{1}{2} A^{2}
$$

Where is average net profit in tourism industry in the country annually. Undoubtedly, we are seeking conditions for the first-order derivative, which is an optimal point on interval ), and the second-order derivative, which is for the maximized answer of .

4.1 Theorem. On the assumption that the average advertising investments in tourism industry ${ }^{4} A>0$, then the optimal net profit of the industry $\left(\pi^{*}\right)$ in one year equals to the advertising investments over WOM influencing rate $(\omega)$ multiplied by positive number $(\varphi)$ (i.e., $\left.\pi^{*}=\varphi A / \omega\right)$.

Proof. Based on the objective function, the equation (5), in the solution, by taking its firstorder derivative with respect to the $A$, it yields $\partial J / \partial A=\pi \omega \vartheta / 2-A$. We continue to find a maximal condition for $J$. We check the second-order derivative and find $\partial^{2} J / \partial A^{2}=-1<0$. The second derivative provides a sufficient condition for a local (relative) maximized solution. From $\partial J / \partial A=0$, we find $\pi^{*}=2 A / \omega \vartheta$. Since $\vartheta$ is positive constant, for simplicity, we may write $\varphi=2 / \vartheta$, another constant. We now obtain $\pi^{*}=\varphi A / \omega$.

The Theorem reaffirms two key dimensions in the short-term scenario. First, even though advertising expenditures are necessary (i.e., having positive linear relationship with net profit and WOM), Seddighi and Theocharous (2002) suggest that the quality of advertisement is more important than the amount of dollars invested. Second, WOM has a negative influence on tourism industry competitiveness because it can reduce TSC's net profit (see Figure 6). Therefore, WOM affecting rate and advertising efforts may not remain collectively responsible for future marketing directions. To simply put, WOM is good for advertising objective, but not for profitability. Conversely, ad is good for both WOM and profitability (see Figure 7). This is a critical insight particularly in the tourism industry. However, we may look for another equation with a clear sense of long-term relationship particularly on the continuous-time path, which raises a topic for further research.

\section{Conclusion}

This study attempted to capture how to predict traveler demand from the WOM effect, and how to improve tourism competitiveness. By using static demand and quadratic cost function, it was found that optimal profit in tourism industry is generated by advertising efforts rather than WOM. Specifically, although TSC's net profit tends to affect the optimal advertising investment

\footnotetext{
${ }^{4}$ This assumption is derived from the second-order condition
} 


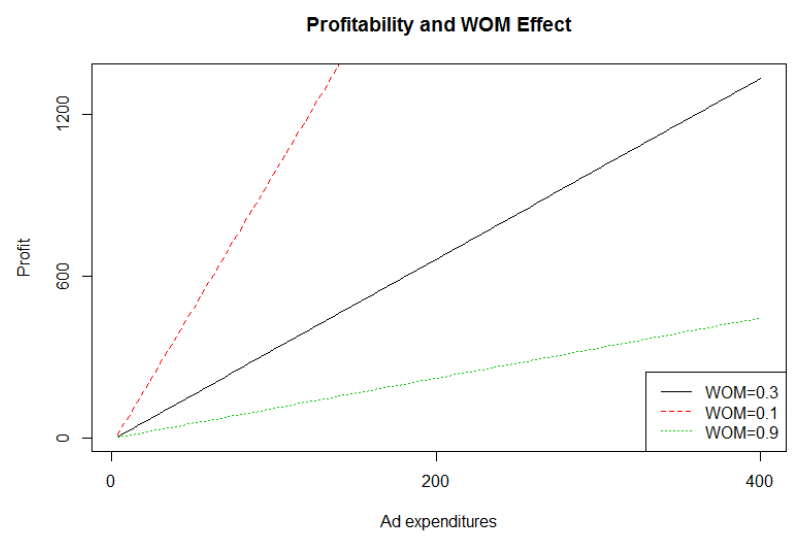

Figure 6. Profitability and WOM influencing rate. The code of R-software is provided in Appendix A.

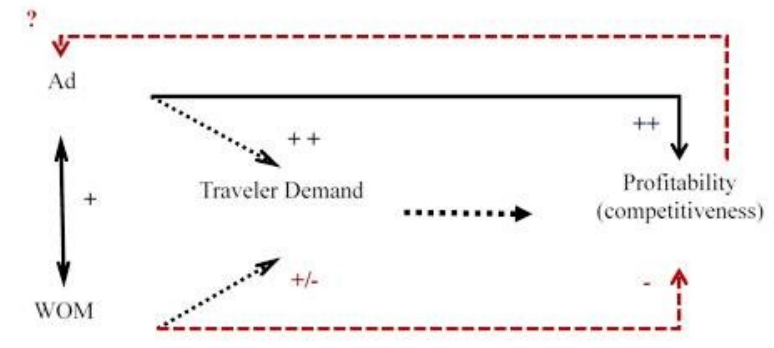

Figure 7. The interpretation

positively, the opposite is the case for WOM. That is, WOM can bring disadvantages to the TSC's advertising campaigns. For example, WOM can create confusion as there are many WOM sources ${ }^{5}$. In addition, negative eWOM and fake reviews can increase visitor (customer)'s uncertainty (Ayeh, Au, \& Law, 2013; Scott \& Orlikowski, 2012; Sun, 2012), regardless of a country's "bad" brand image.

\subsection{Limitation and Future Research Area}

There are several limitations of this study. First, the assumption about representing TSC player or tourism industry as a country may be too strong. Because the government also plays a significant role especially providing some advertising subsidies, or supervising the content of tourism ads for national brand name. Second, the authors are not sure if the model will be applicable prescribed answer, since managers may prefer a trial and error method of finding a solution (Mesterton-Gibbons, 1989).

WOM is a form of online social networks (OSNs) such as Facebook or so-called e-WOM (electronic WOM). Future research should explore how to predict traveler demand in a country by using an OSN. For example, it can be extended by diffusing model built by Kim et al. (2009). Several studies on diffusing WOM using game theory include (Avagyan et al., 2014; Breton, Chauny, \& Zaccour, 1997; Um, 2010; Wei \& Hu, 2013; Zubcsek \& Sarvary, 2011). In addition, as mentioned in the introduction, tourism ministers from the CLMV met last year

\footnotetext{
${ }^{5}$ www.wikipedia.com
} 
to "cooperate to attract foreign visitors... and to develop destination linkages..." . That is, a collaborative alliance on marketing was established. However, as (Palmer (2002)) notes, an irresponsible marketing alliance can permit its members to be free-riders (create a market failure). Has Laos been free-riding its neighboring countries' advertising efforts? This is another interesting question for future research.

\section{References}

Avagyan, V., Esteban-Bravo, M., \& Vidal-Sanz, J. M. (2014). Licensing radical product innovations to speed up the diffusion. European Journal of Operational Research, 239(2), 542-555. doi: 10.1016/j.ejor.2014.05.031

Ayeh, J. K., Au, N., \& Law, R. (2013). “Do We Believe in TripAdvisor?” Examining Credibility Perceptions and Online Travelers' Attitude toward Using User-Generated Content. Journal of Travel Research, 52(4), 437-452. doi: 10.1177/0047287512475217

Boyer, S. L., Edmondson, D. R., Baker, B., \& Solomon, P. (2015). Word-of-Mouth Traditional and Covert Marketing: Comparative Studies. Acadmey of Marketing Studies Journal.

Breton, M., Chauny, F., \& Zaccour, G. (1997). Leader-follower dynamic game of new product diffusion. Journal of Optimization Theory and Applications, 92(1), 77-98. doi: 10.1023/a:1022636029501

Chen, Y. G., Yang, S. Q., \& Wang, Z. J. (2016). Service cooperation and marketing strategies of infomediary and online retailer with eWOM effect. Information Technology \& Management, 17(2), 109-118. doi: 10.1007/s10799-015-0237-1

Chiang, A. C., \& Wainwright, K. (2005). Fundamental Methods of Mathematical Economics: The McGraw-Hill Companies, Inc.

Collier, D. A., \& Evans, J. R. (2007). Operations Management: Goods, Services and Value Chains: Tomson South-Western.

Huang, Z., \& Li, S. X. (2001). Co-op advertising models in manufacturer-retailer supply chains: A game theory approach. European Journal of Operational Research, 135(3), 527-544. doi: http://dx.doi.org/10.1016/S0377-2217(00)00327-1

Hung-Teng, C. (2014). Study on the Chain Restaurants Dynamic Negotiation Games of the Optimization of Joint Procurement of Food Materials. International Journal of Computer Science \& Information Technology, 6(1), 99-112. doi: 10.5121/ijcsit.2014.6107

\footnotetext{
${ }^{6}$ http://kpl.gov.la/En/Detail.aspx?id=15524
} 
Jørgensen, S., \& Zaccour, G. (2014). A survey of game-theoretic models of cooperative advertising. European Journal of Operational Research, 237(1), 1-14. doi: http://dx.doi. org/10.1016/j.ejor.2013.12.017

Kim, S., Han, S., \& Ieee. (2009). An Analytical Way to Find Influencers on Social Networks and Validate their Effects in Disseminating Social Games. New York: Ieee.

Lao Tourism Development Department. (2014). The 2014 Statistical Report on Tourism in Laos. Vientiane, Lao PDR: Ministry of Information, Culture and Tourism.

Lei, M., Liu, X., Li, S., \& Li, X. (2015). Manufacturer uniform pricing and channel choice in random demand. 2015 12th International Conference on Service Systems and Service Management (ICSSSM), 6 pp.-6 pp. doi: 10.1109/icsssm.2015.7170199

Litvin, S. W., Goldsmith, R. E., \& Pan, B. (2008). Electronic word-of-mouth in hospitality and tourism management. Tourism Management, 29(3), 458-468. doi: 10.1016/j.tourman.2007.05.011

Mesterton-Gibbons, M. (1989). A Concrete Approach to Mathematical Modelling: Addi- sonWesley Publishing Company.

Palmer, A. (2002). Cooperative marketing associations: an investigation into the causes of effectiveness. Journal of Strategic Marketing, 10(2), 135-156. doi: $10.1080 / 09652540210125288$

Porter, M. E. (1990). The Competitive Advantage of Nations. New York: The Free Press.

Reece, W. S. (2010). The Economics of Tourism: Pearson Education, Inc.

Sayadi, M. K., \& Makui, A. (2014). Feedback Nash Equilibrium for Dynamic Brand and Channel Advertising in Dual Channel Supply Chain. Journal of Optimization Theory and Applications, 161(3), 1012-1021. doi: 10.1007/s10957-013-0479-1

Scott, S. V., \& Orlikowski, W. J. (2012). Reconfiguring relations of accountability: Materialization of social media in the travel sector. Accounting Organizations and Society, 37(1), 26-40. doi: 10.1016/j.aos.2011.11.005

Seddighi, H. R., \& Theocharous, A. L. (2002). A model of tourism destination choice: a theoretical and empirical analysis. Tourism Management, 23(5), 475-487. doi: http://dx.doi. org/10.1016/S0261-5177(02)00012-2

Slimani, I., El Farissi, I., \& Achchab, S. (2015). Artificial neural networks for demand forecasting: Application using Moroccan supermarket data. 2015 15th International Conference on Intelligent Systems Design and Applications (ISDA). Proceedings, 266-271. doi: 10.1109/isda.2015.7489236 
Song, H., \& Li, G. (2008). Tourism demand modelling and forecasting - A review of Recent research. Tourism Management, 29(2), 203-220. doi: 10.1016/j.tourman.2007.07.016 Sun, M. (2012). How Does the Variance of Product Ratings Matter? Management Science, 58(4), 696-707. doi: 10.1287/mnsc.1110.1458

Um, M.-Y. (2010). A Cross-Cultural Study on Diffusion of Culture-Contents: Focusing on Online Game Contents in Korea and the UK [문화콘텐츠 확산에 관한 비교 문화적 연구: 한국과 영국의 온라인게임 콘텐츠를 중심으로]. korean management review, 39(1), 81-106.

Wei, X.-c., \& Hu, B. (2013). Collaboration mechanism simulation for mobile supply chain under life cycle. Computer Integrated Manufacturing Systems, 19(4), 832-840.

Xiang, L., \& Shan, G. (2013). Modeling collaborative decision-making for supplier and customer in cooperative knowledge creation. 2013 IEEE 4th International Conference on Software Engineering and Service Science (ICSESS), 521-525. doi: 10.1109/icsess.2013.6615363

Y1lmaz, Y., \& Bititci, U. S. (2006). Performance measurement in tourism: a value chain model. International Journal of Contemporary Hospitality Management, 18(4), 341-349. doi: doi:10.1108/09596110610665348

Zubcsek, P.P., \& Sarvary, M. (2011). Advertising to a social network. Qme-Quantitative Marketing and Economics, 9(1), 71-107. doi: 10.1007/s11129-010-9093-9 


\section{Appendix A. The code of R-software}

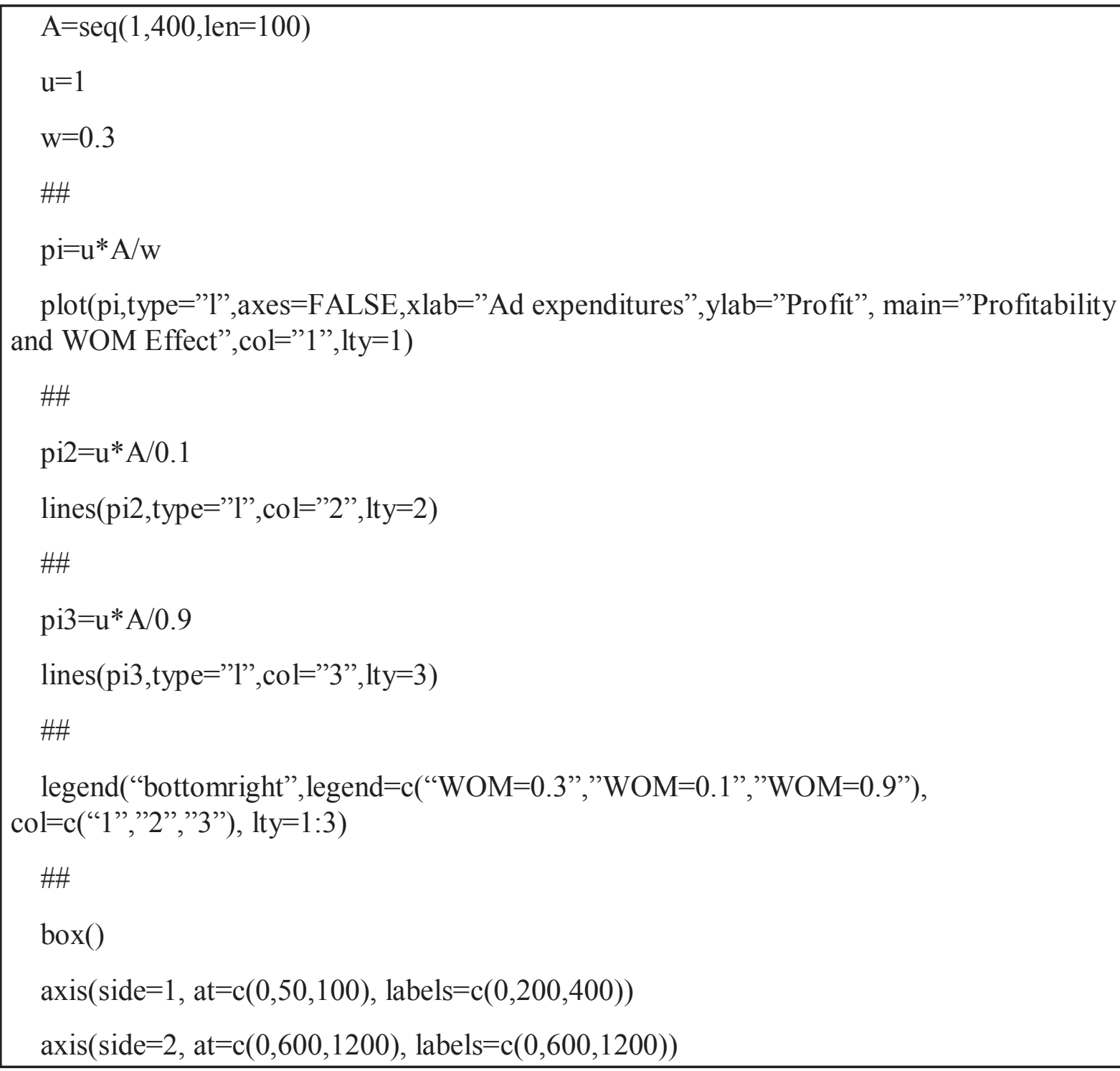

